\title{
EFFECTIVENESS OF APPLYING COOPERATIVE LEARNING MODEL OF COMBINATION TYPE THINK PAIR SHARE (TPS) AND TWO STAY-TWO STRAY (TSTS) WITH CONTEXTUAL APPROACH IN MATHEMATICS LEARNING IN GRADE AT SMPN 3 LANGGUDU IN BIMA DISTRICT
}

\author{
Subhanudin \\ Dosen STKIP Hermon Timika - Papua, Indonesia \\ e-mail : Subhanudin9350@gmail.com
}

\begin{abstract}
The study aims at examining the effectiveness of cooperative learning model combined with Think Pair Share (TSTS) type and Two Stay-Two Stray (TSTS) type with contextual approach in Mathematics learning in grade VIII at SMPN 3 Langgudu in Bima district based on Mathematics learning outcomes, students' activities, and students' response. The type of the study was pre-experimental design with one group pretest-posttest design. The populations of the study were all public junior high schools in Langgudu subdistrict of Bima district of academic year 2017/2018 with the total of 17 schools consisted of 497 students of grade VIII. Simple random sampling technique was used to choose the sample regardless the existing strata in population and obtained one school as the experiment, namely SMPN 3 Langgudu with 40 students of grade VIII. The instruments used in this research were observation sheet of learning implementation, learning result test, observation sheet of students' activities in learning, and questionnaire of students' response on learning. Data collections consisted of students' learning result, data of students' activities in learning, and data of students' response in learning. Data were analyzed by employing descriptive and inferential analys. The results of the study based on descriptive analys reveal that (1) Mathematics learning outcomes in experiment class is in moderate category with the mean score 75.48 , and standard of deviaton 8.25 from the ideal score 100, (2) the classical completeness level in posttest is $85 \%$ in complete category, (3) the mean of normalization gain is in moderate category with the mean score 0.60 , standard of devation 0.11 from the ideal score 1 , (4) the students' activities in learning is in good category with the mean score $3.3,(5)$ the students' response on the implementation of cooperative learning combined with TPS and type TSTS type with contextual approach is in positive category with the mean score 3.3, standard of deviation 0.27 from the ideal score 1. The result based on inferential analysis to examine hypothesis at the level of significance $\alpha$ $=0.05$ using one sample t test with SPSS 20 reveals that the data of learning outcomes in posttest, normalized gain, and data of students' response, it can be concluded that the application of cooperative learning model of Think Pair Share type and Two Stay-Two Stray type with contextual approach is effective to be applied on cube and block learning material in grade VIII at SMPN 3 Langgudu in Bima district.
\end{abstract}

Keywords: Effectiveness, cooperative learning, TPS, TSTS, contextual approach, Mathematics Learning

\section{PENDAHULUAN}

Matematika yang diajarkan di sekolah memiliki peranan yang sangat penting dalam meningkatkan kualitas SDM, karena matematika merupakan salah satu sarana untuk berpikir logis, analitis, kreatif dan sistematis yang memudahkan dalam membuat inovasi baru dalam kehidupan sehari-hari terutama dalam memahami dan memecahkan suatu masalah matematika dengan baik. Selain itu, sebagai salah satu disiplin ilmu, matematika juga menjadi pendukung bagi 
keberadaan ilmu-ilmu yang lain. Oleh karena itu, siswa diharapkan dapat menguasai matematika pada tingkat tertentu, sehingga berguna sebagai bekal siswa dalam berkompetensi pada massa yang akan datang.

Ada beberapa jenis model pembelajaran kooperatif, diantaranya model pembelajaran kooperatif tipe Think Pair Share (TPS) dan model pembelajaran kooperatif tipe Two Stay-Two Stray (TSTS). Model pembelajaran kooperatif kombinasi tipe Think Pair Share dan tipe Two Stay-Two Stray adalah suatu model pembelajaran yang dikembangkan dengan menggabungkan/mengadaptasi sintaks dari model pembelajaran kooperatif tipe Think Pair Share dan model pembelajaran kooperatif tipe Two Stay-Two Stray. Modifikasi tersebut dilakukan karena tidak ada satu model pembelajaran yang sempurna, setiap model pembelajaran masing-masing mempunyai kelebihan dan kelemahan ketika digunakan dalam proses pembelajaran. Dengan demikian, kombinasi dua atau lebih model pembelajaran akan saling menetralisasi kelemahan yang ada. Salah satu alasan lain penulis menerapkan model pembelajaran kooperatif kombinasi tipe Think Pair Share (TPS) dan tipe Two Stay-Two Stray (TSTS) dengan pendekatan kontekstual karena sebelumnya belum pernah diterapkan dalam pembelajaran matematika.

Sehubungan dengan hal tersebut, peneliti tertarik untuk penelitian guna untuk mengetahui keefektifan penerapan model pembelajaran kooperatif kombinasi tipe Think Pair Share (TPS) dan tipe Two Stay-Two Stray (TSTS) dengan pendekatan kontekstual dalam pembelajaran matematika kelas VIII pada SMP Negeri 3 Langgudu.

Berdasarkan latar belakang masalah, maka rumusan masalah umum dalam penelitian ini adalah apakah penerapan model pembelajaran kooperatif kombinasi tipe Think Pair Share (TPS) dan tipe Two Stay-Two Stray (TSTS) dengan pendekatan kontekstual efektif dalam pembelajaran matematika di kelas VIII SMP Negeri 3 Langgudu?

Untuk menjawab rumusan masalah tersebut, akan diuraikan masalah khusus sebagai berikut: (1) Bagaimana hasil belajar siswa setelah diajar dengan model pembelajaran kooperatif kombinasi tipe Think Pair Share (TPS) dan tipe Two Stay-Two Stray (TSTS) dengan pendekatan kontekstual di SMP Negeri 3 Langgudu? (2) Bagaimana gambaran aktivitas siswa selama diajar dengan model pembelajaran kooperatif kombinasi tipe Think Pair Share (TPS) dan tipe Two Stay-Two Stray (TSTS) dengan pendekatan kontekstual di SMP Negeri 3 Langgudu? (3) Bagaimana gambaran respons siswa selama diajar dengan model pembelajaran kooperatif kombinasi tipe Think Pair Share (TPS) dan tipe Two Stay-Two Stray (TSTS) dengan pendekatan kontekstual di SMP Negeri 3 Langgudu?

Tujuan yang ingin dicapai pada penelitian ini adalah untuk mengetahui keefektifan pembelajaran kooperatif kombinasi tipe Think Pair Share (TPS) dan tipe Two Stay-Two Stray (TSTS) dengan pendekatan kontekstual dalam pembelajaran matematika di kelas VIII SMP Negeri 3 Langgudu. Secara khusus penelitian ini adalah sebagai berikut: (1) Untuk mengetahui hasil belajar siswa setelah diajar dengan model pembelajaran kooperatif kombinasi tipe Think Pair Share (TPS) dan tipe Two Stay-Two Stray (TSTS) dengan pendekatan kontekstual di SMP Negeri 3 Langgudu. (2) Untuk mengetahui gambaran aktivitas siswa selama diajar dengan model pembelajaran kooperatif kombinasi tipe Think Pair Share (TPS) dan tipe Two Stay-Two Stray (TSTS) dengan pendekatan kontekstual di SMP Negeri 3 Langgudu. (3) Untuk mengetahui gambaran respons siswa selama diajar dengan model pembelajaran kooperatif kombinasi tipe Think Pair Share (TPS) dan tipe Two Stay-Two Stray (TSTS) dengan pendekatan kontekstual di SMP Negeri 3 Langgudu. 


\section{TINJAUAN PUSTAKA}

Eiggen dan Kauchak dalam Firdaus, (2009:58) mengemukakan bahwa pembelajaran dikatakan efektif bila siswa secara aktif dilibatkan dalam pengorganisasian dan penemuan informasi (pengetahuan). Siswa tidak hanya secara pasif menerima pengetahuan yang diberikan guru. Hasil pembelajaran ini tidak hanya meningkatkan keterampilan berpikir siswa.

Keefektifan pembelajaran adalah pengaruh yang ditimbulkan/disebabkan oleh adanya suatu kegiatan pembelajaran yang menunjukan sejauh mana tingkat keberhasilan yang dicapai setelah proses pembelajaran yang dilakukan. Suatu pembelajaran dikatakan efektif apabila mencapai sasaran yang diinginkan, baik dari segi tujuan pembelajaran maupun hasil belajar siswa yang maksimal.

Adapun keefektifan pembelajaran yang dimaksud dalam penelitian ini merujuk pada kualitas dari 3 aspek yang terkait dengan proses pembelajaran di kelas antara lain: (1) hasil belajar siswa (2) aktivitas siswa dalam pembelajaran, dan (3) respons siswa terhadap pembelajaran.

Hasil belajar matematika adalah kemampuan-kemampuan tertentu yang telah dicapai atau dikuasai siswa yang meliputi aspek kognitif, efektif maupun psikomotor setelah mengalami proses belajar matematika, yang diukur berdasarkan kriteria kemampuan yang ditetapkan, yang kualitasnya diperoleh melalui tes hasil belajar matematika dengan menggunakan indikator-indikator sesuai konteks materi matematika dalam ranah-ranah yang diukur.

Aktivitas Belajar Siswa adalah rangkaian kegiatan yang dilakukan siswa dalam mengikuti pembelajaran sehingga menimbulkan perubahan perilaku belajar pada diri siswa, misalnya dari tidak tahu menjadi tahu atau dari tidak mampu melakukan kegiatan menjadi mampu melakukan kegiatan.
Respons siswa adalah tanggapan dan komentar siswa tentang aspek-aspek pembelajaran meliputi: perangkat pembelajaran, suasana belajar di kelas, cara guru menyajikan materi, tanggapan siswa mengenai model pembelajaran yang diterapkan. Pada lembar observasi respons siswa setiap indikator menggunakan skala sangat setuju, setuju, tidak setuju, sangat tidak setuju.

Pembelajaran kooperatif merupakan model pembelajaran dengan menggunakan sistem pengelompokan, yaitu antara 4-6 orang yang mempunyai latar belakang kemampuan akademik, jenis kelamin, rasa tau suku yang berbeda (heterogen) dimana siswa bekerja sama dan saling membantu dalam belajar untuk mencapai tujuan bersama.

Model pembelajaran kooperatif tipe Think Pair Share Pertama kali dikembangkan oleh Frag Lyman dan koleganya di Universitas Maryland sesuai yang dikutip Arends dalam Trianto (2007: 60), menyatakan bahwa TPS merupakan suatu cara yang efektif untuk membuat variasi suasana pola diskusi kelas. Dengan asumsi bahwa semua resitasi atau diskusi membutuhkan pengaturan untuk mengendalikan kelas secara keseluruhan, dan prosedur yang digunakan dalam Think Pair Share dapat memberi siswa lebih banyak waktu berfikir, untuk merespons dan saling membantu. Guru memperkirakan hanya melengkapi penyajian singkat atau siswa membaca tugas, atau situasi yang menjadi tanda tanya. Sekarang guru menginginkan siswa mempertimbangkan lebih banyak apa yang telah dijelaskan dan dialami. Guru memilih menggunakan Think Pair Share untuk membandingkan tanya jawab kelompok keseluruhan.

Model pembelajaran kooperatif tipe

Two Stay Two Stray pertama kali dikembangkan oleh Spencer Kagan pada tahun (1992). Two Stay Two Stray berasal dari bahasa Inggris yang berarti "dua tinggal dua tamu". Model pembelajaran kooperatif tipe Two Stay Two Stray merupakan sistem 
pembelajaran kelompok dengan tujuan agar siswa dapat saling bekerjasama, bertanggung jawab, saling membantu memecahkan masalah, saling mendorong untuk berprestasi, dan juga melatih siswa untuk bersosialisasi dengan baik.

Pembelajaran dengan pendekatan Contextual Teaching and Learning (CTL), merupakan konsep belajar yang membantu guru menghubungkan antara materi yang diajarkan dengan situasi dunia nyanta peserta didik dan mendorong peserta didik membuat hubungan antara pengetahuan yang dimilikinya dengan penderapannya dalam kehidupan mereka sebagai anggota keluarga dan masyarakat. Dengan konsep itu, hasil pembelajaran diharapkan lebih bermakna bagi peserta didik. Proses pembelajaran berlangsung alamiah dalam bentuk kegiatan peserta didik bekerja dan mengalami, bukan mentransfer pengetahuan dari guru ke peserta didik.

Model pembelajaran kooperatif kombinasi tipe TPS dan tipe TSTS dengan pendekatan kontekstual adalah suatu metode pembelajaran yang dikembangkan dengan menggabungkan/mengadaptasi sintaks dari model pembelajaran kooperatif tipe TPS dan tipe TSTS. Modifikasi tersebut dilakukan karena tidak ada satu model pembelajaran yang sempurna,setiap model pembelajaran masing-masing mempunyai kelebihan dan kelemahan ketika digunakan dalam proses pembelajaran.

Adapun hipotesisnya adalah "Pembelajaran dengan menggunakan model pembelajaran kooperatif kombinasi tipe Thnk Pair Share dan tipe Two Stay-Two Stray dengan pendekatan kontekstual efektif untuk diterapkan pada siswa kelas VIII SMP Negeri 3 Langgudu.

\section{METODE PENELITIAN}

Penelitian ini adalah penelitian kuantitatif eksperimen yang melibatkan satu kelas (One Grup) sebagai kelas eksperimen atau kelas perlakuan. Penelitian ini bertujuan mengetahui keefektifan penerapan model pembelajaran kooperatif kombinasi tipe Think Pair Share dan model pembelajaran kooperatif tipe Two Stay-Two Stray dalam pembelajaran matematika siswa kelas VIII SMP Negeri 3 Langgudu.

Desain Penelitian yang digunakan dalam penelitian ini adalah "One Group Pretest-Posttest Design yang merupakan salah satu bentuk desain dari Pre-Experimental. Skema desain penelitian dapat digambarkan sebagai berikut:

\begin{tabular}{|c|c|c|}
\hline $\mathrm{O}_{1}$ & $\mathrm{X}$ & $\mathrm{O}_{2}$ \\
\hline
\end{tabular}

(Sugiyono, 2009:75)

Keterangan:

$\mathrm{O}_{1}$ : Skor pretest

$\mathrm{X}$ : Perlakuan (treatment), penerapan model pembelajaran kooperatif kombinasi tipe TPS dan TSTS

$\mathrm{O}_{2}$ : Skor posttest

Hipotesis yang diuji dalam penelitian ini adalah data hasil belajar matematika siswa setelah penerapan model pembelajaran kooperatif kombinasi tipe Think Pair Share dan tipe Two Stay-Two Stray dengan pendekatan kontekstual. Berdasarkan hipotesis penelitian yang diuraikan pada bab sebelumnya, maka hipotesis yang akan diuji adalah sebagai berikut:

- Rata-rata hasil belajar siswa setelah diajar dengan menggunakan pembelajaran kooperatif kombinasi tipe Think Pair Share (TPS) dan tipe Two Stay-Two Stray (TSTS) dengan pendekatan kontekstual pembelajaran lebih dari 70 (KKM).

$\mathrm{H}_{0}: \mu_{1} \leq 70$

$\mathrm{H}_{1}: \mu_{1}>70$

- Rata-rata gain ternormalisasi siswa yang diajar dengan menggunakan model pembelajaran kooperatif kombinasitipe Think Pair Share (TPS) dan tipe Two Stay-Two Stray (TSTS) dengan pendekatan kontekstual lebih dari 0,3.

$$
\begin{aligned}
& \mathrm{H}_{0}: \mu_{\mathrm{g}} \leq 0,3 \\
& \mathrm{H}_{1}: \mu_{\mathrm{g}}>0,3
\end{aligned}
$$


Untuk menguji hipotesis penelitian 1 dan 2 digunakan statistik parametrik dengan uji $t$. Dengan taraf signifikan untuk menguji hipotesis digunakan $\alpha=0,05$. Jenis uji $t$ yang digunakan adalah one sample t test dengan bantuan SPSS versi 20. Adapun kriteria pengujian sebagai berikut:

$\mathrm{H}_{0}$ diterima jika $p$-value $\geq 0,05$

$\mathrm{H}_{0}$ diterima jika $p$-value $<0,05$

Hipotesis yang diuji dalam penelitian ini selain hasil belajar adalah respons siswa setelah penerapan model pembelajaran kooperatif kombinasi tipe Think Pair Share dan tipe Two Stay-Two Stray. Berdasarkan hipotesis penelitian yang diuraikan pada bab sebelumnya, maka hipotesis yang diuji adalah sebagai berikut:

$$
\begin{aligned}
& \mathrm{H}_{0}: \mu_{\mathrm{r}} \leq 2,5 \\
& \mathrm{H}_{1}: \mu_{\mathrm{r}}>2,5
\end{aligned}
$$

Untuk menguji Hipotesis penelitian digunakan statistik parametrik dengan uji $t$. Dengan taraf signifikan untuk menguji hipotesis digunakan $\alpha=0,05$. Jenis uji $t$ yang digunakan adalah adalah one sample $t$ test dengan bantuan SPSS versi 20. Adapun kriteria pengujian sebagai berikut:

$\mathrm{H}_{0}$ diterima jika $p$-value $\geq 0,05$

$\mathrm{H}_{0}$ diterima jika $p$-value $<0,05$

\section{HASIL PENELITIAN}

Analisis statistik deskriptif bertujuan untuk mendeskripsikan variasi data yang telah dikumpulkan melalui instrument penelitian pada kelas eksperimen yang diajar dengan model pembelajaran kooperatif kombinasi tipe Think Pair Share dan tipe Two Stay-Two Stray. Adapun data akan dianalisis adalah data tentang keterlaksanaan pembelajaran, data hasil belajar siswa, data aktivitas siswa dalam pembelajaran, data respons siswa terhadap perangkat pembelajaran dan pembelajarannya.

Tabel 4.1. Hasil Observasi Keterlaksanaan Pembelajaran dengan Penerapan Model pembelajaran kooperatif kombinasi tipe Think Pair Share dan tipe Two Stay-Two Stray.

Jurnal Ilmu Sosial dan Pendidikan

\begin{tabular}{llll}
\hline Pertemuan & $\begin{array}{l}\text { Rata- } \\
\text { Rata }\end{array}$ & Kategori & $\begin{array}{l}\text { Keterangan } \\
\text { Kategori }\end{array}$ \\
\hline Pertemuan I & 3,3 & Baik & $2,5 \leq \bar{x}<3,5$ \\
Pertemuan II & 3,3 & Baik & $2,5 \leq \bar{x}<3,5$ \\
Pertemuan III & 3,4 & Baik & $2,5 \leq \bar{x}<3,5$ \\
Pertemuan IV & 3,5 & Sangat Baik & $3,5 \leq \bar{x} \leq 4$ \\
Pertemuan V & 3,7 & Sangat Baik & $3,5 \leq \bar{x} \leq 4$ \\
Pertemuan VI & 3,9 & Sangat Baik & $3,5 \leq \bar{x} \leq 4$ \\
\hline Rata-Rata Total & 3,5 & Sangat Baik & $3,30<$ TKP $\leq$ \\
& & & 4,00
\end{tabular}

Berdasarkan uraian di atas, dapat disimpulkan bahwa secara deskriptif Keterlaksanaan Model pembelajaran kooperatif kombinasi tipe Think Pair Share dan tipe Two Stay-Two Stray memenuhi kriteria keefektifan.

Tabel 4.3. Distribusi Frekuensi dan Persentasi Skor Hasil Belajar Matematika Siswa Kelas VIII SMP Negeri 3 Langgudu Dengan Penerapan Model Pembelajaran Kooperatif Kombinasi Tipe Think Pair Share dan tipe Two Stay-Two Stray.

\begin{tabular}{cccccc}
\hline Interval & Kategori & \multicolumn{3}{c}{ Pretest } & Posttest \\
\cline { 3 - 6 } & & Frekuensi & Persentasi & Frekuensi & Persentasi \\
\hline $0-54$ & Sangat Rendah & 37 & $92 \%$ & - & - \\
$55-64$ & Rendah & 3 & $8 \%$ & 3 & $8 \%$ \\
$65-79$ & Sedang & - & - & 25 & $62 \%$ \\
$80-89$ & Tinggi & - & - & 10 & $25 \%$ \\
$90-100$ & Sangat tinggi & - & - & 2 & $5 \%$ \\
\hline
\end{tabular}

Berdasarkan kriteria ketuntasan minimal (KKM) yang berlaku di SMP Negeri 3 Langgudu yakni 70, maka tingkat pencapaian ketuntasan hasil belajar matematika siswa secara klasikal pada kelas eksperimen dengan penerapan model pembelajaran kooperatif kombinasi tipe Think Pair Share dan tipe Two Stay-Two Stray, dapat dilihat pada tabel berikut.

Tabel 4.4. Distribusi Ketuntasan Hasil Belajar Siswa

\begin{tabular}{cccc}
\hline & KKM & \multicolumn{2}{c}{ Persentase Ketuntasan } \\
& & Klasikal $(\%)$ \\
& & Tuntas & $\begin{array}{c}\text { Tidak } \\
\text { Tuntas }\end{array}$ \\
\hline Pretest & & - & $100 \%$ \\
Posttest & 70 & $85 \%$ & $15 \%$ \\
\hline
\end{tabular}


Tabel 4.4 di atas menunjukkan bahwa persentase siswa yang tuntas secara klasikal sebesar $85 \%$, sehingga dapat disimpulkan bahwa secara deskriptif hasil belajar matematika siswa pada penerapan model pembelajaran kooperatif kombinasi tipe Think Pair Share dan tipe Two Stay-Two Stray memenuhi kriteria ketuntasan.

Tabel 4.9. Distribusi Frekuensi dan Persentasi Skor Respons Siswa Terhadap Pelaksanaan Pembelajaran Kelas VIII SMP Negeri 3 Langgudu Setelah Penerapan Model Pembelajaran Kooperatif Kombinasi Tipe Think Pair Share dan tipe Two Stay-Two Stray.

\begin{tabular}{cccc}
\hline Skor & Kategori & Frekuensi & Persentase \\
\hline $3,5 \leq \mathrm{RS} \leq 4,0$ & Sangat Positif & 8 & $20 \%$ \\
$2,5 \leq \mathrm{RS}<3,5$ & Positif & 32 & $80 \%$ \\
$1,5 \leq \mathrm{RS}<2,5$ & Negatif & - & - \\
$\mathrm{RS}<1,5$ & Sangat Negatif & - & - \\
\hline
\end{tabular}

Tabel di atas menunjukkan bahwa rata-rata respons siswa terhadap pelaksanaan pembelajaran setelah penerapan model pembelajaran kooperatif kombinasi tipe Think Pair Share dan tipe Two Stay-Two Stray sebesar 3,3 berada pada kategori positif, dimana $80 \%$ siswa memperoleh nilai pada interval $2,5 \leq \mathrm{RS}<3,5$.

Tabel 4.10. Uji Normalitas Hasil Belajar Siswa

\begin{tabular}{rrrr}
\hline & \multicolumn{3}{c}{ Kolmogorov-Smirnov $^{\mathrm{a}}$} \\
\cline { 2 - 4 } & Statistic & Df & Sig. \\
\hline Posttest & 0,103 & 40 & $0,200^{\circ}$ \\
\hline
\end{tabular}

Dari hasil uji normalitas pada table 4.10 di atas diperoleh data bahwa hasil belajar siswa diperoleh nilai $p$-value $=0,200$ untuk uji normalitas kolmogorov-smirnov. P-value lebih dari $\alpha=0,05$ sehingga dapat disimpulkan bahwa data tentang hasil belajar siswa berasal dari populasi yang distribusi normal.

Tabel 4.13. Analisis Inferensial One Sample $t$ Test Untuk Skor Posttest Siswa

Jurnal Ilmu Sosial dan Pendidikan

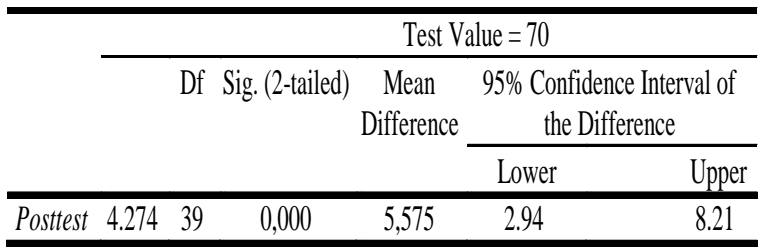

Berdasarkan hasil analisis yang dilakukan diperoleh nilai $p$-value $<0,001$ dengan nilai $\alpha=0,05$ sehingga nilai $p$-value < $\alpha$. Dengan demikian $\mathrm{H}_{0}$ ditolak. Ini berarti rata-rata hasil belajar siswa setelah diajar dengan model pembelajaran kooperatif kombinasi tipe Think Pair Share dan tipe Two Stay-Two Stray dengan pendekatan kontekstual lebih dari 70 (KKM).

Tabel 4.14. Analisis Inferensial One Sample t Test Untuk Skor Peningkatan Hasil Belajar Siswa

\begin{tabular}{cccccc}
\hline & \multicolumn{4}{c}{ Test Value = 0.3} \\
\hline & Df & $\begin{array}{c}\text { Sig. (2- } \\
\text { tailed) }\end{array}$ & Mean & \multicolumn{2}{c}{ Difference Confidence Interval of the } \\
& & & & \multicolumn{2}{c}{ Difference } \\
\cline { 3 - 6 } & & & & Lower & Upper \\
\hline Gain 31,752 & 39 & ,000 & 0,59776 & 0,5597 & 0,6358 \\
\hline
\end{tabular}

Berdasarkan hasil analisis yang dilakukan dipeoleh nilai $p$-value $<0,001$ dengan nilai $\alpha=0,05$ sehingga nilai $p$-value $<\alpha$. Dengan demikian $\mathrm{H}_{0}$ ditolak, ini berarti rata-rata gain ternormalisasi siswa yang diajar dengan model pembelajaran kooperatif kombinasi tipe Think Pair Share dan tipe Two Stay-Two Stray lebih dari 0,3.

Tabel 4.15. Analisis Inferensial One Sample $t$ Test Untuk Rata-Rata Skor Respons Siswa

\begin{tabular}{|c|c|c|c|c|c|}
\hline & \multicolumn{5}{|c|}{ Test Value $=2.5$} \\
\hline & \multirow[t]{2}{*}{ Df } & \multirow[t]{2}{*}{$\begin{array}{l}\text { Sig. }(2- \\
\text { tailed })\end{array}$} & \multirow[t]{2}{*}{$\begin{array}{c}\text { Mean } \\
\text { Difference }\end{array}$} & \multicolumn{2}{|c|}{$\begin{array}{c}95 \% \text { Confidence Interval of the } \\
\text { Difference }\end{array}$} \\
\hline & & & & Lower & Upper \\
\hline Respons 72.978 & 39 & 0,000 & 0,10616 & 0,1032 & 0,1091 \\
\hline
\end{tabular}

Berdasarkan hasil analisis yang dilakukan diperoleh nilai $p$-value $<0,001$ dengan nilai $\alpha=0,05$ sehingga nilai $p$-value < 
$\alpha$. Dengan demikian $\mathrm{H}_{0}$ ditolak, ini berarti rata-rata skor respons siswa yang diajar dengan model pembelajaran kooperatif kombinasi tipe Think Pair Share dan tipe Two Stay-Two Stray lebih dari 2,5.

Tabel 4.16. Pencapaian Keefektifan Pembelajaran

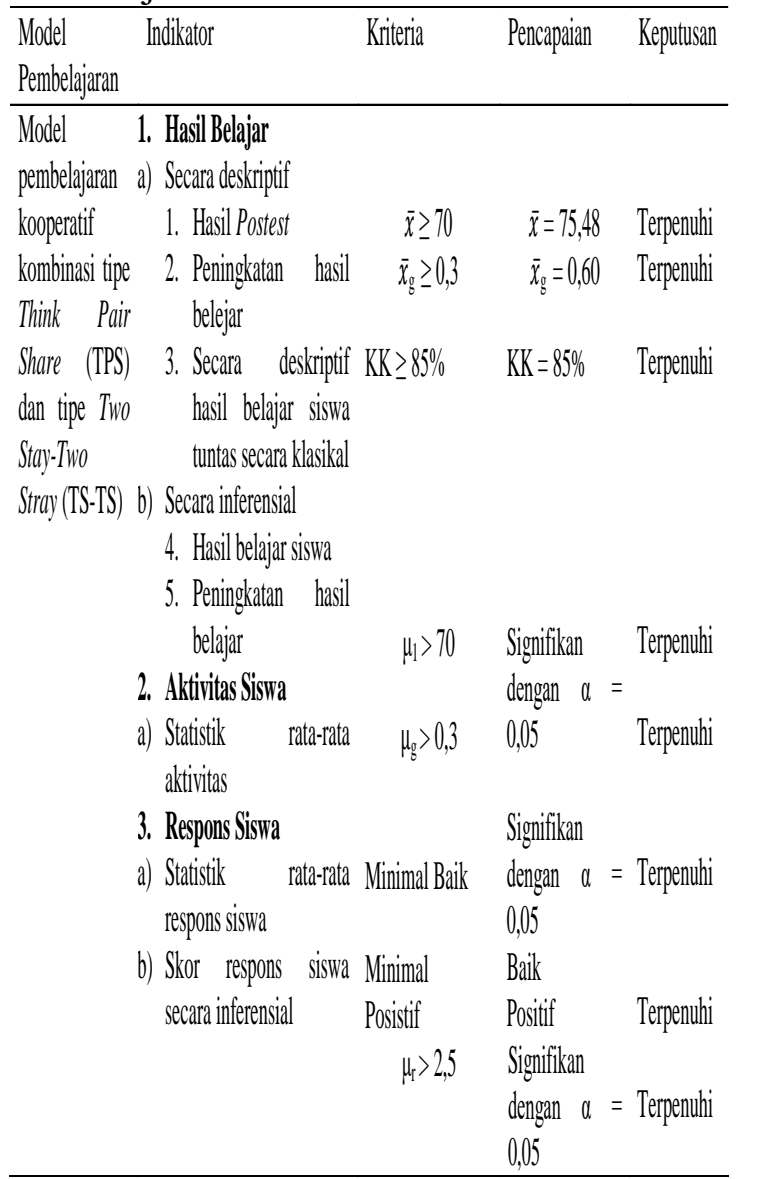

Berdasarkan tabel 4.16 di atas, terlihat semua indikator keefektifan memenuhi kriteria pencapaian keefektifan pembelajaran maka model pembelajaran kooperatif kombinasi tipe Think Pair Share dan tipe Two Stay-Two Stray efektif diterapkan pada materi kubus dan balok pada siswa SMP Negeri 3 Langgudu.

\section{PEMBAHASAN HASIL PENELITIAN}

Penelitian ini dilaksanakan di SMP Negeri 3 Langgudu pada kelas VIII sebagai kelas eksperimen dengan jumlah sampel sebanyak 40 siswa penelitian ini bertujuan untuk mengetahui keefektifan pembelajaran

Jurnal Ilmu Sosial dan Pendidikan matematika di kelas VIII pada SMP Negeri 3 Langgudu dengan menerapkan model pembelajaran kooperatif kombinasi tipe Think Pair Share dan tipe Two Stay-Two Stray.

\section{Hasil Belajar Siswa}

Hasil penelitian ini menunjukan bahwa hasil belajar matematika siswa yang diajar dengan model pembelajaran kooperatif kombinasi tipe Think Pair Share dan tipe Two Stay-Two Stray ditinjau dari tingkat kemampuan siswa berada pada kategori sedang dengan tingkat ketuntasan klasikal mencapai $85 \%$ serta pengetahuan siswa menunjukkan peningkatan yang signifikan setelah belajar dengan menerapkan model pembelajaran kooperatif kombinasi tipe Think Pair Share dan tipe Two Stay-Two Stray. Hal ini ditunjukkan oleh nilai rata-rata gain ternomalisasi siswa sebesar 0,60 yang berada pada kategori sedang. Secara keseluruhan pembelajaran matematika dengan menerapkan model pembelajaran kooperatif kombinasi tipe Think Pair Share dan tipe Two Stay-Two Stray dapat meningkatkan kemampuan siswa dalam memahami materi kubus dan balok.

Dari uraian diatas, disimpulkan bahwa dalam tahapan-tahapan model pembelajaran kooperatif kombinasi tipe Think Pair Share dan tipe Two Stay-Two Stray dapat meningkatkan hasil belajar matematika siswa kelas VIII SMP Negeri 3 Langgudu pada materi kubus dan balok, sehingga pembelajaran ini efektif untuk diterapkan.

\section{Aktivitas Siswa}

Hasil pengamatan aktivitas siswa yang memperlihatkan tingkat aktivitas baik pada pelaksanaan model pembelajaran kooperatif kombinasi tipe Think Pair Share dan tipe Two Stay-Two Stray menggambarkan tingginya gairah siswa terlibat secara aktif dalam pembelajaran. Gairah belajar yang tinggi tersebut selain karena mereka senang dengan pembelajaran secara berkelompok seperti yang telah dijelaskan sebelumnya ditambah dengan adanya keinginan yang besar dari mereka untuk menyelesaikan LKS secara individu sebelum mendiskusikan dengan 
pasangannya dan anggota kelompokknya serta berbagai kelompok yang lain.

Hasil dari pengamatan aktivitas di atas sesuai dengan teori yang dikemukakan oleh Webb (dalam Suradi, 2005:4) yaitu belajar kooperatif dapat meningkatkan aktivitas siswa secara umum dan memudahkan interaksi siswa secara khusus. Sehingga siswa secara aktif bekerja sama, saling membantu memecahkan permasalahan-permasalahan matematika yang dihadapi. Di dalam kelompoknya para siswa saling memberikan pengalaman, saling memberi dan menerima sehingga setiap anggota memberikan konstribusi terhadap keberhasilan kelompok.

\section{Respons Siswa}

Rata-rata respons siswa setelah penerapan model pembelajaran kooperatif kombinasi tipe Think Pair Share dan tipe Two Stay-Two Stray sebesar 3,3 berada pada interval $2,5 \leq \mathrm{RS}<3,5$ dengan kategori positif.

Dari hasil respons siswa tersebut, menunjukkan bahwa pembelajaran yang dilaksanakan telah memberi kebermaknaan pada siswa, tercipta suasana yang nyaman bagi siswa untuk belajar dan membuat siswa aktif serta meningkatkan motivasi belajar siswa khususnya pada materi pelajaran matematika. Hal ini pula terlihat dari beberapa komentar tertulis yang diberikan pada angket respons siswa yang mengatakan senang terhadap proses pembelajaran ini dan menyarankan agar model pembelajaran ini diterapkan pada materi yang lain.

\section{Keefektifan Model pembelajaran} kooperatif kombinasi tipe Think Pair Share dan tipe Two Stay-Two Stray dengan pendekatan kontekstual.

Hasil penelitian ini menunjukkan bahwa Aktivitas siswa minimal berada pada kategori baik, respons siswa terhadap perangkat dan pembelajarannya berada pada kategori positif, dan hasil belajar matematika siswa yang diajar dengan model pembelajaran kooperatif kombinasi tipe Think Pair Share dan tipe Two Stay-Two Stray pada materi Jurnal Ilmu Sosial dan Pendidikan kubus dan balok ditinjau dari tingkat kemampuan siswa berada pada kategori sedang dengan tingkat ketuntasan klasikal mencapai $85 \%$ serta pengetahuan siswa menunjukkan peningkatan yang signifikan setelah belajar dengan menerapkan model pembelajaran kooperatif kombinasi tipe Think Pair Share dan tipe Two Stay-Two Stray.

Jadi, berdasarkan hasil analisis data dan pembahasan diatas, dapat disimpulkan bahwa prasyarat berupa keterlaksanaan pembelajaran terpenuhi, aktivitas siswa efektif, respons siswa terhadap pembelajaran dengan penerapan model pembelajaran kooperatif kombinasi tipe Think Pair Share dan tipe Two Stay-Two Stray positif dan hasil belajar secara klasikal tuntas. Dengan demikian, model pembelajaran kooperatif kombinasi tipe Think Pair Share dan tipe Two Stay-Two Stray efektif diterapkan pada siswa kelas VIII SMP Negeri 3 Langgudu pada materi kubus dan balok.

\section{KESIMPULAN}

Berdasarkan hasil penelitian dan pembahasan, maka kesimpulan dalam penelitian ini adalah sebagai berikut: (1) Berdasarkan hasil belajar siswa, model pembelajaran kooperatif kombinasi tipe Think Pair Share dan tipe Two Stay-Two Stray dinyatakan efektif. Hasil belajar siswa yang diajar dengan model pembelajaran kooperatif kombinasi tipe Think Pair Share dan tipe Two Stay-Two Stray berada pada kategori sedang rata-rata 75,48 dari skor maksimum ideal 100 dan standar deviasi 7,25. Serta terjadi peningkatan hasil belajar siswa yang signifikan dengan rata-rata nilai gain $0,60,(2)$ Berdasarkan aktivitas siswa, model pembelajaran kooperatif kombinasi tipe Think Pair Share dan tipe Two Stay-Two Stray dinyatakan efektif. Aktifitas siswa pada model pembelajaran kooperatif kombinasi tipe Think Pair Share dan tipe Two Stay-Two Stray berada pada kategori baik dengan ratarata nilai aktivitas 3,3, (3) Berdasarkan respons siswa, model pembelajaran kooperatif kombinasi tipe Think Pair Share dan tipe Two 
Stay-Two Stray kooperatif efektif. Respons siswa pada model pembelajaran kooperatif kombinasi tipe Think Pair Share dan tipe Two Stay-Two Stray berada pada kategori positif dengan rata-rata nilai respons 3,3, (4) Model pembelajaran kooperatif kombinasi tipe Think Pair Share dan tipe Two Stay-Two Stray efektif diterapkan pada materi kubus dan balok di kelas VIII SMP Negeri 3 langgudu.

\section{SARAN}

Berdasarkan kesimpulan di atas, maka peneliti menyarankan beberapa hal yang perlu diperhatikan: (1) Bagi guru: model pembelajaran kooperatif kombinasi tipe Think Pair Share dan tipe Two Stay-Two Stray hendaknya dapat menjadi bahan pertimbangan dalam memilih model pembelajaran di sekolah dan dijadikan sebagai alternatif pilihan guru dalam pembelajaran terutama untuk mata pelajaran matematika. Hal ini disebabkan karena model pembelajaran tersebut dapat meningkatkan hasil belajar siswa, melibatkan aktivitas siswa secara optimal, (2) Bagi peneliti: dibidang pendidikan yang berminat melanjutkan penelitian ini diharapkan agar mencermati segala keterbatasan penelitian ini dan hendaknya lebih mengembangkan penelitian tentang Pembelajaran dengan menggunakan model kooperatif kombinasi tipe Think Pair Share (TPS) dan Two Stay-Two Stray (TSTS) dengan pendekatan kontekstual agar dapat menuntaskan problem pendidikan secara menyeluruh.

\section{DAFTAR PUSTAKA}

Abraham, Sheva. 12 Desember 2011. Makalah Pendekatan Kontekstual Learning.

(Online),(http://s1pgsd.blogspot.co.id/2 011/12/makalah-pendekatan

kontekstual-learning.html,diakses $\quad 10$ Februari 2018)

Baroh. 2010. Efektifitas Metode Simulasi Pada Materi Peluang Siswa kelas IX SMP Negeri 1 Semarang. Jurnal UIN Sunan Apel Surabaya

Jurnal Ilmu Sosial dan Pendidikan
Daryanto. 2013. Inovasi Pembelajaran Efektif. Bandung: Yrama Widya

Eggen \& Kauchak. 1997. Education Psychologi. New jersey: Prentice Hall

Firdaus. 2009. Efektivitas Pembelajaran Kooperatif Tipe NHT dalam Pembelajaran Matematika di SMA. Tesis. Tidak Diterbitkan. Makassar: PPs UNM.

Hajir, Muhamad. 2011. Keefektifan Model Pembelajaran Langsung Setting Koopratif Tipe Think Pair Share pada Kelas X SMA Negeri 2 Pangkajene. Tesis. Tidak diterbitkan Makassar: Program Pasca Sarjan UNM.

Hake, R.R. 1999. Analyzing Change/Gain Scores .Artikel .http://physics.indiana.edu/ sdi/Analyzi ngChange-Gain.pdf. (Online). (Diakses 10 Februari 2018).

Huda, Miftahul. 2012. Cooperative Learning. Yogyakarta: Pustaka Pelajar

Husniah. 2014. Model Pembelajaran Matematika di Sekolah Dasar. Bandung: PT Remaja Rosdakarya.

Husniah. 2014. Pengaruh Model Pembelajaran Kooperatif Terhadap Hasil Belajar Matematika ditinjau dari motivasi belajar. Tesis. Tidak diterbitkan. Makassar: Program Pascasarjana UNM Makssar.

Junaryadi, B. 2012. Pengembangan Perangkat Pembelajaran Matematika Model Kooperatif Tipe Two Stay Two Stray (TSTS) dengan Pendekatan Kontruktivisme untuk Meningkatkan Kemampuan Komunikasi Matematika Siswa. Semarang: Universitas Negeri Semarang. Indonesia. Journal of Primary Educational JPE (1) (2012).

Junaidi, wawan. 2010. Cara Meningkatkan Aktivitas Belajar Siswa. http:wawanjunaidi.blogspot. com/2010/07/aktivitas-belajarsiswa.html(10 Februari 2018)

Juliantara, Ketut. 2010. Aktifitas Belajar. Download dari 
http://edukasi.Kompasiana.

Com/2010/04/11/Aktifitas-belajar Pada

Tanggal 7 Maret 2011 Pukul 15.30 WIB.

Jusnadi. 2016. Efektivitas Model Kooperatif

Tipe Two Stay Two Stray (TSTS)

Dengan Pendekatan Matemtika

Realistik Dalam Pembelajaran

Matematika Di Kelas VII SMP Negeri

11 Bulukumba. Tesis. Tidak diterbitkan.

Makassar: Program Pascasarjana UNM

Makssar.

Khasanah, U. 2011. Keefektifan Penggunaan

Metode Two Stay Two Stray (Ts-Ts)

Pada Keterampilan Membaca Bahasa

Jerman Di Sma $N \quad 1$ Sedayu.

Yogyakarta: Universitas Negeri

Yogyakarta.

Lie, A. 2004. Cooperative Learning

Mempraktikkan Cooperative Learing di

Ruang-Ruang Kelas. Jakarta: Grasindo.

Lisnasari. 2015. Efektifitas Model

Pembelajaran Generatif dengan Strategi

Write-Pair-Switch dalam Pembelajaran

Matematika Siswa Kelas X SMA Negeri 9 Makassar.

Tesis.TidakDiterbitkan. Makassar: PPs UNM.

Maemanah,S. 2007. Matematika untuk SMP/MTs Kelas VIII. Bogor: Arya Duta.

Mutadi. 2008. Bergelut dengan Si Asyik Matematika. Jakarta: Listafariska Putra.

Negoro \& Harahap. 2014. Ensiklopedia Matematika, Cet VII. Bogor: Ghalia Indonesia.

Nurani. Lisna. 2013. Peningkatan Hasil Belajar Materi Perkalian Aljabar dengan Menggunakan Alat Peraga Blokar. Jurnal Ruang Kartesian, (30), 226-232.

Nurdin. 2016. Model Pembelajaran Menumbuhkembangkan Kemampuan Metakognitif. Makassar: Pustaka Refleksi.

Rapiuddin. 2013. Komparasi Pembelajaran Kooperatif Tipe Two Stay-Two Stray Jurnal Ilmu Sosial dan Pendidikan dan Tipe Jigsaw Pada Materi Trigonometri di Kelas X SMA Pangkajene. Tesis.Tidak diterbitkan. Makassar: Program PascaSarjana UNM. Rasyid, H. 2009. Penilaian Hasil Belajar. Bandung: Wacana Prima.

Riyanto, Y. 2009. Paradigma Baru Pembelajaran. Jakarta: Kencana.

Rizki, Novianti. 2012. Pengembangan Desain Pembelajaran Matematika Model Kooperatif Tipe Two Stay Two Stray (TSTS) dengan Pendekatan Realistic Pada Siswa Kelas VII A SMP Negeri 2 Kalukku. Tesis. Tidak diterbitkan. Makassar: Program Pascasarjana UNM.

Rusman, 2010. Model-Model Pembelajaran: Mengembangkan Profesionalisme Guru. Jakarta: PT Rajagrafindo Persada.

Sagala, Syaiful. 2010. Konsep dan Makna Pembelajaran. Bandung: Alfabeta.

Slavin, Robert E. 2005. Cooperative Learning. Terjemahan oleh Narulita Yusron. 2015. Bandung: Nusa Media.

Sugiyono. 2009. Metode Penelitian Pendidikan Pendekatan Kuantitatif, Kualitati fdan $R$ \& $D$. Bandung: Alfabeta.

Sumiati \& Asra. 2008. Metode Pembelajaran. Bandung: Wacana Prima

Supardi. 2015. Penilaian Autentik. Pembelajaran Afektif, Kognitif dan Psikomotor. Jakarta: PT Raja Grafindo Persada

Sukino \& Simangungsong, W. 2007. Matematika untuk SMP kelas VIII. Jakarta

Suprijono, A. 2009. Cooperative Learning. Yogyakarta: Pustaka Pelajar.

Suradi. 2005. Interaksi Siswa SMP dalam Belajar Matematika secara Kooperatif. Disertasi. Tidak diterbitkan. Surabaya: Program Pasca Sarjan UNS.

Suwarto. 2013. Pengembangan Tes Diagnostik dan Pembelajaran Panduan Praktis Bagi Pandidik dan Calon Pendidik. Yogyakarta: Pustaka Pelajar 
Suyatno. 2009. Menjelajah Pembelajaran Inovatif. Surabaya: Masmedia Buana Pustaka.

Suyanto . 2013. Menjadi Guru Profesional: Strategi Meningkatkan Kualifikasi dan Kualitas Guru di Era Global. Jakarta: Erlangga.

Trianto. 2007. Model-Model Pembelajaran Inovatif Berorientasi Konstruktivistik. Jakarta: Prestasi Pustaka.

Trianto. 2009. Mendesain Model Pembelajaran Inovatif-Progresif. Konsep Landasan dan Implementasinya pada KTSP. Surabaya: Predana Media Grup.

UU RI no. 20 Tahun 2003 "Sistem Pendidikan Nasional Beserta Peraturanperaturannya". 2003 Jakarta: Departemen Pendidikan Nasional 